\title{
Environmental toxic metal contaminants and risk of cardiovascular disease: systematic review and meta-analysis
}

\author{
Rajiv Chowdhury, ${ }^{1}$ Anna Ramond, ${ }^{1}$ Linda M O'Keeffe, ${ }^{2,3}$ Sara Shahzad, ${ }^{1}$ Setor K Kunutsor, ${ }^{4,5,6}$ \\ Taulant Muka, ${ }^{7}$ John Gregson, ${ }^{8}$ Peter Willeit, ${ }^{1,9}$ Samantha Warnakula, ${ }^{1}$ Hassan Khan, ${ }^{10}$ \\ Susmita Chowdhury, ${ }^{1}$ Reeta Gobin, ${ }^{11}$ Oscar H Franco, ${ }^{7}$ Emanuele Di Angelantonio ${ }^{1,12,13}$
}

For numbered affiliations see end of article.

Correspondence to: SShahzad ss2231@medschl.cam.ac.uk Additional material is published online only. To view please visit the journal online.

Cite this as: $B M J$ 2018;362:k3310 http://dx.doi.org/10.1136/bmi.k3310

Accepted: 4 July 2018

\section{ABSTRACT}

OBJECTIVE

To conduct a systematic review and meta-analysis of epidemiological studies investigating the association of arsenic, lead, cadmium, mercury, and copper with cardiovascular disease.

\section{DESIGN}

Systematic review and meta-analysis.

DATA SOURCES

PubMed, Embase, and Web of Science searched up to December 2017.

\section{REVIEW METHODS}

Studies reporting risk estimates for total

cardiovascular disease, coronary heart disease, and stroke for levels of arsenic, lead, cadmium, mercury, or copper were included. Two investigators independently extracted information on study characteristics and outcomes in accordance with PRISMA and MOOSE guidelines. Relative risks were standardised to a common scale and pooled across studies for each marker using random effects metaanalyses.

RESULTS

The review identified 37 unique studies comprising 348259 non-overlapping participants, with 13033 coronary heart disease, 4205 stroke, and 15274 cardiovascular disease outcomes in aggregate. Comparing top versus bottom thirds of baseline levels, pooled relative risks for arsenic and lead were 1.30 (95\% confidence interval 1.04 to 1.63 ) and 1.43 (1.16 to 1.76 ) for cardiovascular disease, 1.23 (1.04 to 1.45 ) and 1.85 (1.27 to 2.69 ) for coronary heart disease, and 1.15 (0.92 to 1.43$)$ and 1.63 (1.14 to 2.34) for stroke. Relative risks for cadmium and copper were 1.33 (1.09 to 1.64 ) and 1.81 (1.05 to 3.11) for cardiovascular disease, 1.29 (0.98 to 1.71 ) and 2.22 (1.31 to 3.74) for coronary heart disease, and 1.72 (1.29 to 2.28) and 1.29 (0.77 to 2.17) for stroke. Mercury had no distinctive association with

\section{WHAT IS ALREADY KNOWN ON THIS TOPIC}

In recent years, exposures to environmental toxic metals of hydrogeological origin (eg, arsenic, lead, cadmium, mercury, and copper) have become a major global public health concern

There are increasing suggestions that exposure to toxic metals may be an independent risk factor for cardiovascular disease

\section{WHAT THIS STUDY ADDS}

Exposure to arsenic, lead, and cadmium showed a positive and approximately linear association with the risk of cardiovascular disease

Mercury was not associated with any cardiovascular outcomes

cardiovascular outcomes. There was a linear doseresponse relation for arsenic, lead, and cadmium with cardiovascular disease outcomes.

\section{CONCLUSIONS}

Exposure to arsenic, lead, cadmium, and copper is associated with an increased risk of cardiovascular disease and coronary heart disease. Mercury is not associated with cardiovascular risk. These findings reinforce the importance of environmental toxic metals in cardiovascular risk, beyond the roles of conventional behavioural risk factors.

\section{Introduction}

In recent decades, exposures to environmental toxic metals of hydrogeological origin (eg, arsenic, lead, cadmium, mercury, and copper) have become a global public health concern owing to their potential deleterious health effects in humans. ${ }^{1-5}$ For example, according to the World Health Organization and the International Agency for Research on Cancer, arsenic and cadmium are group I human carcinogens and arsenic is the world's second leading water-borne cause of mortality. ${ }^{67}$ Metalloids such as arsenic often fall into the category of heavy metals due to similarity in properties. $^{8}$ Chronic exposure to high levels of arsenic, cadmium, and other toxic metals has also been associated with higher risk of cancers of the bladder, kidney, liver, lung, and skin. ${ }^{9}$ Emerging evidence suggests that these toxic metals may have adverse effects on these outcomes even at lower concentrations, ${ }^{5}$ which might be prevalent in many parts of the world.

Additionally, there are increasing suggestions that exposure to arsenic and other (often co-occurring) toxic metals may be an independent risk factor for cardiovascular disease. ${ }^{10} 11$ However, despite their well established role as immunotoxicants and carcinogens, the associations between environmental toxic metals and risk of clinical cardiovascular disease outcomes remain less well characterised. Although there are several individual reports published on the topic, they vary greatly in sufficient detail (eg, on associations with diverse cardiovascular outcomes) and in study design (eg, ecological versus individuallevel associations). Interpretation of the earlier reviews is difficult, as they were mostly systematic reviews without quantitative synthesis of estimates, ${ }^{12}{ }^{13}$ and focused typically on a single toxic metal, ${ }^{14-16}$ or combined estimates from ecological study designs (which are prone to suffer from substantial bias and confounding). ${ }^{17}$ Additionally, whether a detrimental association with cardiovascular disease exists in low 
or medium levels of exposure (ie, typical for many global regions) remains unclear. Therefore, given the global nature of the toxic metal contamination, accurate characterisation of the associations between these environmental contaminants and cardiovascular disease is essential to understand the aetiology of cardiovascular disease, and critically, to inform public health efforts to reduce toxic metal exposure.

To help clarify the evidence, we aimed to summarise the available population based epidemiological studies in a comprehensive systematic review and meta-analysis to determine the associations of selected metal contaminants (measured at individual level) with the risk of first-ever cardiovascular outcomes (including cardiovascular disease, coronary heart disease, and stroke), and quantify any dose-response relation. For the current study, we focus primarily on five major toxic metals or metalloids, owing to their global public health relevance. We have included arsenic, lead, cadmium, and mercury, which have been included in the World Health Organization's list of "Ten chemicals of major public health concern" and have potential mechanistic links to cardiovascular diseases. ${ }^{1819}$ In addition, we have included copper as it appears to promote atherosclerosis by enhancing the oxidation of LDL-cholesterol and may increase the risk of clinical cardiovascular disease outcomes. ${ }^{20-23}$

\section{Methods}

Search strategy

This study was conducted in accordance with the PRISMA and MOOSE guidelines (see fig 1

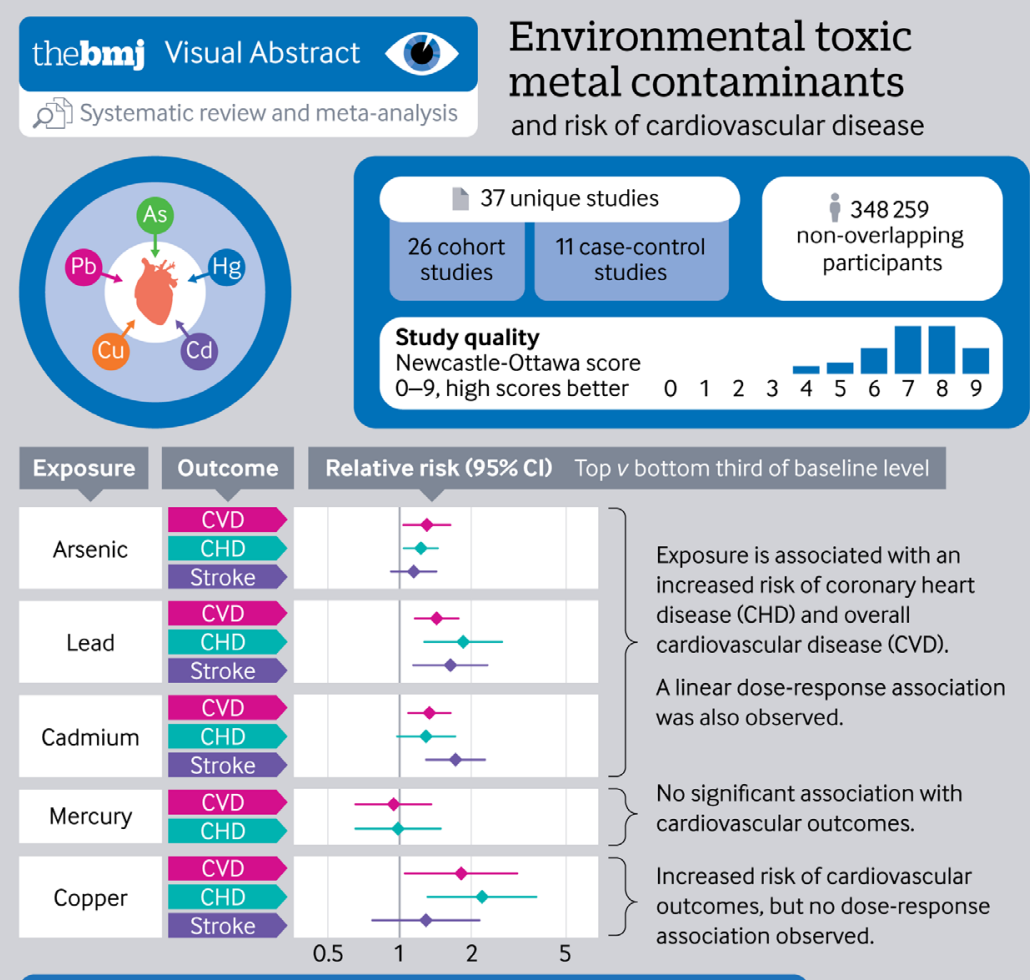

thelomi Read the full article online http://bit.ly/BMJtox and supplementary materials, table S1). We comprehensively searched the MEDLINE, Embase, and Web of Science electronic databases to identify studies published until 5 December 2017 (date of last search), which examined the association between arsenic, lead, cadmium, mercury, and copper with primary outcomes of interest. The primary outcomes were coronary heart disease (defined as non-fatal myocardial infarction, angina, coronary revascularisation (ie, percutaneous transluminal coronary angioplasty or coronary artery bypass surgery, or coronary heart disease death), stroke (defined as fatal or nonfatal stroke), and composite cardiovascular disease (comprised of coronary heart disease and stroke). The computer based searches combined search terms related to the toxic metal exposures (eg, arsenic ${ }^{\star}$, lead ${ }^{\star}$, mercury ${ }^{\star}$, etc) and outcomes of interest (eg, cardiovascular disease ${ }^{\star}$, myocardial infarction ${ }^{\star}$, stroke ${ }^{\star}$, etc), without any language restriction. Further studies were sought by manually searching reference lists of the relevant articles. When relevant information was unavailable, efforts were made to contact corresponding authors. Details of the search strategy are presented in supplementary materials, appendix 1.

\section{Selection criteria}

We included studies if they met the following initial search criteria: were prospective cohort, case-control, or nested case-control in design; had sampled from healthy (ie, participants or referents, where appropriate, were based on initially healthy participants) or general populations (ie, populations with both healthy and prevalent cases of cardiovascular disease at baseline); assessed toxic metal exposure at individual level rather than aggregate level (eg, individual-level exposure to arsenic in drinking water); or reported risk estimates for cardiovascular disease, coronary heart disease, or stroke, for at least one toxic metal. We excluded studies for the following reasons: they only reported on mean levels and standard deviations of toxic metals in cases and non-cases; they only assessed exposure to toxic metals using a self reported dietary measure; or were cross-sectional or ecological in design. Two independent reviewers screened the search results to assess conformity with selection criteria, with disagreement resolved with a third reviewer. In cases of multiple publications from a single study, we used the most up to date information.

\section{Data extraction and quality assessment}

Data on the following characteristics were extracted independently by two investigators using standardised protocols: sample size; study design; sampling population; location (defined as Europe, North America, and the Asia-Pacific region); year of baseline survey; study design; age range of participants at baseline; sex; mean levels of environmental contaminants at baseline; sample type (serum, plasma, or adipose tissue), storage temperature, assay methods; duration of follow-up; numbers of disease outcomes of interest and reported effect estimates with 


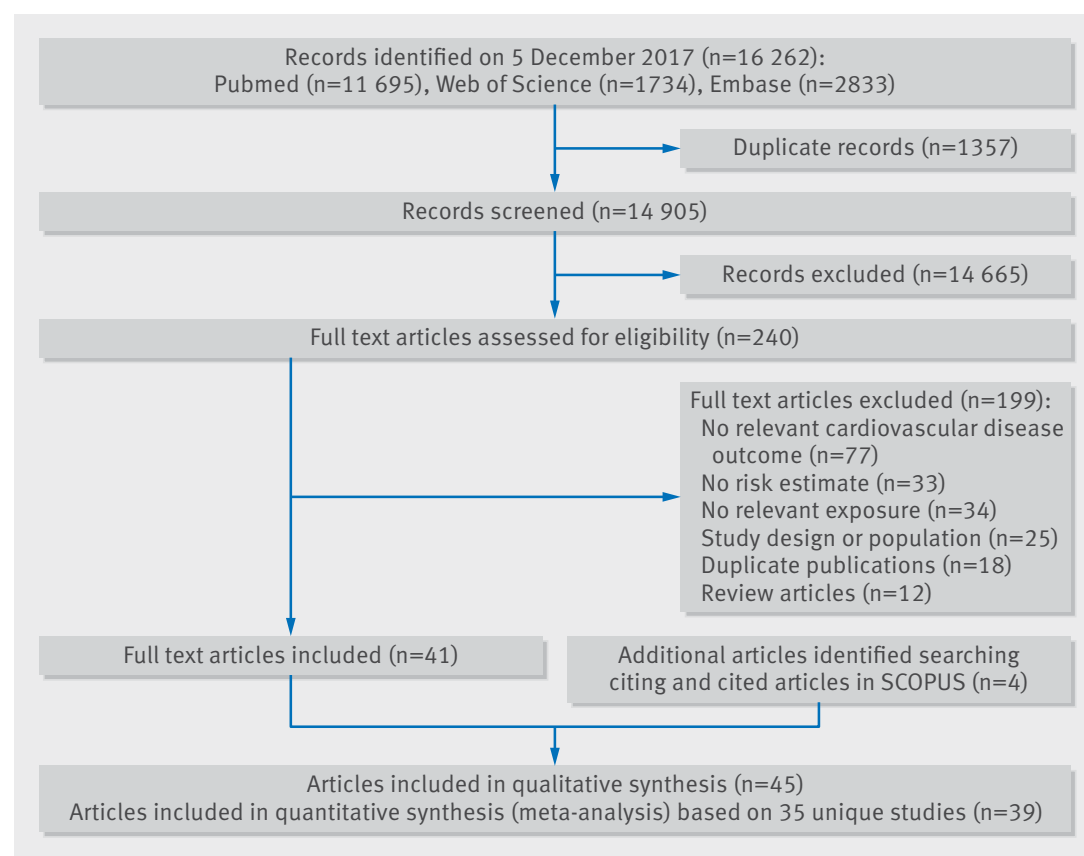

Fig 1 | PRISMA flow diagram of search strategy log relative risk for a 1 standard deviation increase (or equivalently, as 2.18/2.54 times the log relative risk for a comparison of extreme quarters). Standard errors of the log relative risks were calculated using published confidence limits and were transformed in the same way. For example, the study by Kromhout et al reported a relative risk of cardiovascular disease of 1.06 (95\% confidence interval 0.47 to 2.37) comparing the top versus bottom quartile of lead exposure, corresponding to a log relative risk of 0.058 and standard errors (log relative risk) of $0.41 .^{26}$ The conversion of risk estimates to top versus bottom third exposure of lead in this study is performed as follows: $\log$ relative risk (top $v$ bottom third) $=(2.18 / 2.54)^{\star} 0.058=0.05$ and standard errors log relative risk (top $v$ bottom third) $=(2.18 / 2.54)^{\star} 0.41=0.35$.

We calculated summary relative risks by pooling the study-specific estimates using a random- effects model that included between study heterogeneity (parallel analyses used fixed-effect models). We assessed the consistency of findings across individual studies by standard $\chi^{2}$ tests and the $\mathrm{I}^{2}$ statistic. $^{27}$ We assessed heterogeneity between observational cohorts by comparing results from studies grouped according to prespecified study level characteristics (such as study design, location, year of baseline survey, duration of follow-up, numbers of outcomes recorded, outcome definition, degree of statistical adjustment used, and sample type) using meta-regression. In particular, for studies investigating the association of arsenic with cardiovascular disease outcomes, the impact of the measurement source (biomarker $v$ water) on risk estimates was assessed in subgroup analyses. We assessed evidence of publication bias across studies using funnel plots and Egger test for outcomes where at least three studies were available. ${ }^{28}$

We performed dose-response meta-analyses using generalised least-squares trend estimation (GLST) analysis as described by Greenland and Longnecker. ${ }^{29}$ We estimated study-specific slopes (linear trends) from the correlated natural logs of the relative risks across toxic metal exposure categories. Only studies that reported the number of cases, non-cases, person years of follow-up, and the relative risks with the variance estimates for at least three quantitative exposure categories were included. The median or mean level of the toxic metal in the original scale was assigned to the corresponding relative risk for each exposure category. If data were not available, we estimated the median using the midpoint of each category. When the highest or lowest category was open, we assumed it to be of the same amplitude as the adjacent category. Potential nonlinear dose-response relations were examined by modelling levels of toxic metals using restricted cubic splines. ${ }^{30} \mathrm{~A} \mathrm{P}$ value for nonlinearity was calculated by testing the null hypothesis that the coefficient of the second spline is equal to zero. All statistical tests were two sided and used a significance level of $\mathrm{P}<0.05$. We performed all analyses using Stata version 12 (StataCorp, College Station, TX). 


\section{Patient involvement}

No patients were involved in setting the research question or the outcome measures, nor were they involved in developing plans for design or implementation of the study. No patients were asked to advise on interpretation or writing up of results. There are no plans to disseminate the results of the research to study participants or the relevant patient community.

\section{Results}

\section{Study level characteristics}

A total of 37 unique studies reporting on 348259 distinct patients were identified, including relevant available data on arsenic (12 studies), lead (11), cadmium (8), mercury (9), and copper (6) (see table 1, fig 1 , and supplementary material, table S3).

Overall, 12 of these studies were based in North America, 17 in Europe, and 8 in the Asia-Pacific region. Thirty three studies were prospective (26 cohorts and 7 nested case-control (ie, case-control study nested in a cohort study) or case-cohort studies) and four studies were case-control studies. Environmental contaminant measurement methods used in each study are detailed in supplementary materials, table S4. Primary sources of measurement for arsenic were individual-level drinking water (6 studies), urine (4), and toenails (2). Lead and copper levels in blood were measured in all studies. Cadmium levels in urine were reported in three studies, in blood in four studies, and in toenails in one study. Exposure to mercury

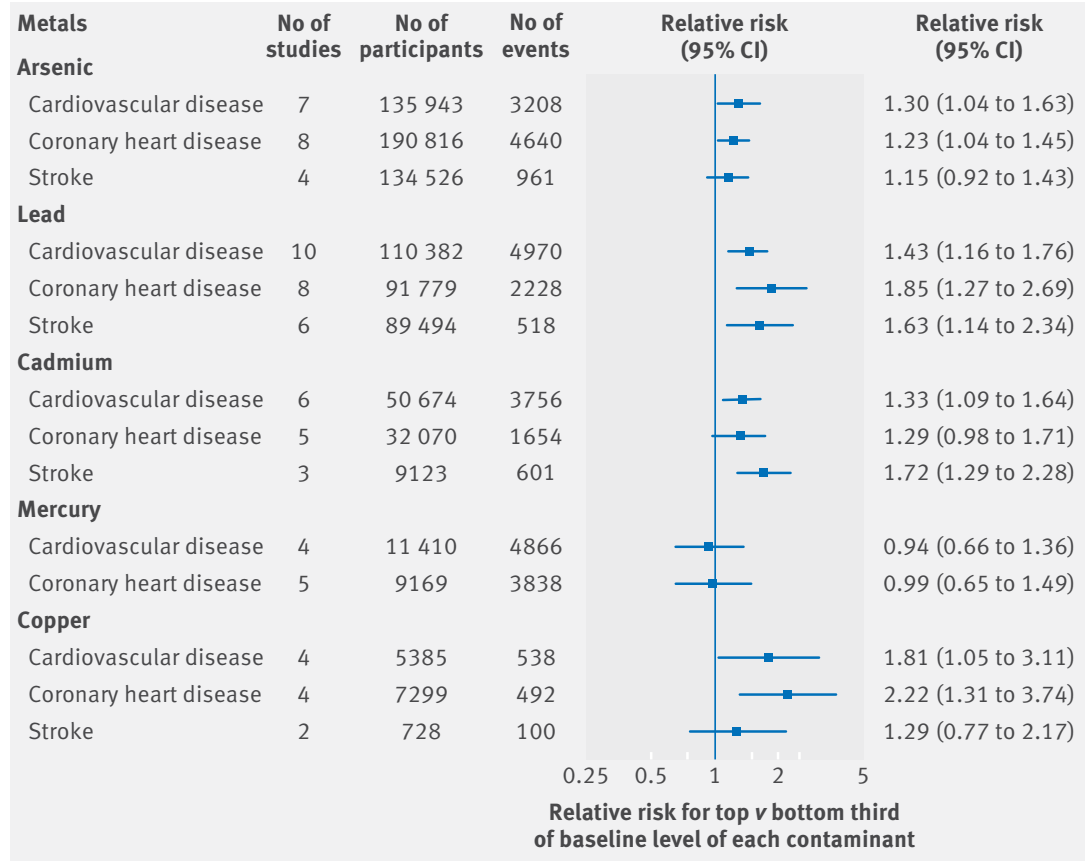

Fig 2 | Summary of the association of environmental contaminants with cardiovascular outcomes. Pooled risk estimates were calculated using random effects meta-analyses. The relative risk compares the risk for each outcome in individuals in the top third with those in the bottom third of baseline levels of the environmental contaminants (ie, extreme thirds). Risk estimates from separate studies were typically adjusted for basic demographics (eg, age, sex, systolic blood pressure, smoking, history of diabetes, etc) levels was measured in hair (2 studies), blood (4), or toenail (3) samples (supplementary material, table S4). Average baseline levels of contaminants in studies reporting baseline exposure ranged from $3.7 \mu \mathrm{g} / \mathrm{L}$ to $4.9 \mu \mathrm{g} / \mathrm{L}$ for arsenic in urine and $0.7 \mu \mathrm{g} / \mathrm{L}$ to 131.1 $\mu \mathrm{g} / \mathrm{L}$ for arsenic in drinking water, whereas baseline levels of lead, cadmium, mercury, and copper in blood ranged from $2.6 \mu \mathrm{g} / \mathrm{dL}$ to $44.3 \mu \mathrm{g} / \mathrm{dL}, 0.44 \mu \mathrm{g} / \mathrm{L}$ to 1.3 $\mu \mathrm{g} / \mathrm{L}, 0.004 \mu \mathrm{g} / \mathrm{L}$ to $3.5 \mu \mathrm{g} / \mathrm{L}$, and $0.96 \mathrm{mg} / \mathrm{L}$ to 1.27 $\mathrm{mg} / \mathrm{L}$ respectively. Table 2 and table 3 show that study quality assessed using the Newcastle-Ottawa scale varied. Most studies were of medium to high quality (score $\geq 7$ ). Twelve studies (10 cohort, 2 case-control) were of low quality.

\section{Associations between environmental contaminants} and the risk of cardiovascular disease outcomes

Thirty five studies were included in the meta-analysis of environmental contaminants and cardiovascular disease outcomes. Six studies (one reporting on arsenic, two on cadmium, three on mercury) which did not use an appropriate assessment of heavy metal exposure (ie, use of cadmium levels in toenails) or did not adjust for important confounders of heavy metal exposure (eg, smoking for cadmium or seafood intake for mercury) were excluded from the analysis (table 1). In total, 14706, 12 033, and 3613 cases of cardiovascular disease, coronary heart disease, and stroke, respectively, across 35 contributing studies were included in the meta-analysis. The total follow-up duration ranged from five to 36 years in the prospective studies. Twenty three studies adjusted for conventional risk factors for cardiovascular disease including age, sex, and sociodemographic factors (ethnicity, education, income) as well as additional risk factors such as smoking status, blood pressure, lipids, and medical history. Thirteen studies adjusted for age, sex, and sociodemographic factors. Three studies adjusted for age and sex only. Figure 2 shows the summary plot for cardiovascular disease, coronary heart disease, and stroke comparing participants in the top third with those in the bottom third of various environmental contaminants. Figure 3, figure 4, and figure 5 show the forest plots for each separate outcome.

Arsenic, lead, cadmium, and copper were significantly associated with the risk of coronary heart disease, with respective relative risks of 1.23 (95\% confidence interval 1.04 to 1.45 ), 1.85 (1.27 to 2.69), 1.29 ( 0.98 to 1.71 ), and 2.22 (1.31 to 3.74). There was no association of mercury levels with coronary heart disease, relative risk of 0.99 ( 0.65 to 1.49 ). There was evidence of heterogeneity in coronary heart disease estimates across studies for most environmental contaminants $\left(\mathrm{I}^{2}=78 \%, \mathrm{P}<0.001\right.$ for arsenic; $\mathrm{I}^{2}=66 \%$, $\mathrm{P}=0.005$ for lead; $\mathrm{I}^{2}=52 \%, \mathrm{P}=0.08$ for cadmium; $\mathrm{I}^{2}=85 \%, \mathrm{P}<0.001$ for mercury; and $\mathrm{I}^{2}=67 \%, \mathrm{P}=0.03$ for copper;).

Similar to the risk of coronary heart disease, arsenic, lead, cadmium, and copper levels were also associated with an increased risk of cardiovascular disease (respective relative risks of 1.30, 95\% confidence 
Table 1 | Summary of the studies included in the systematic review

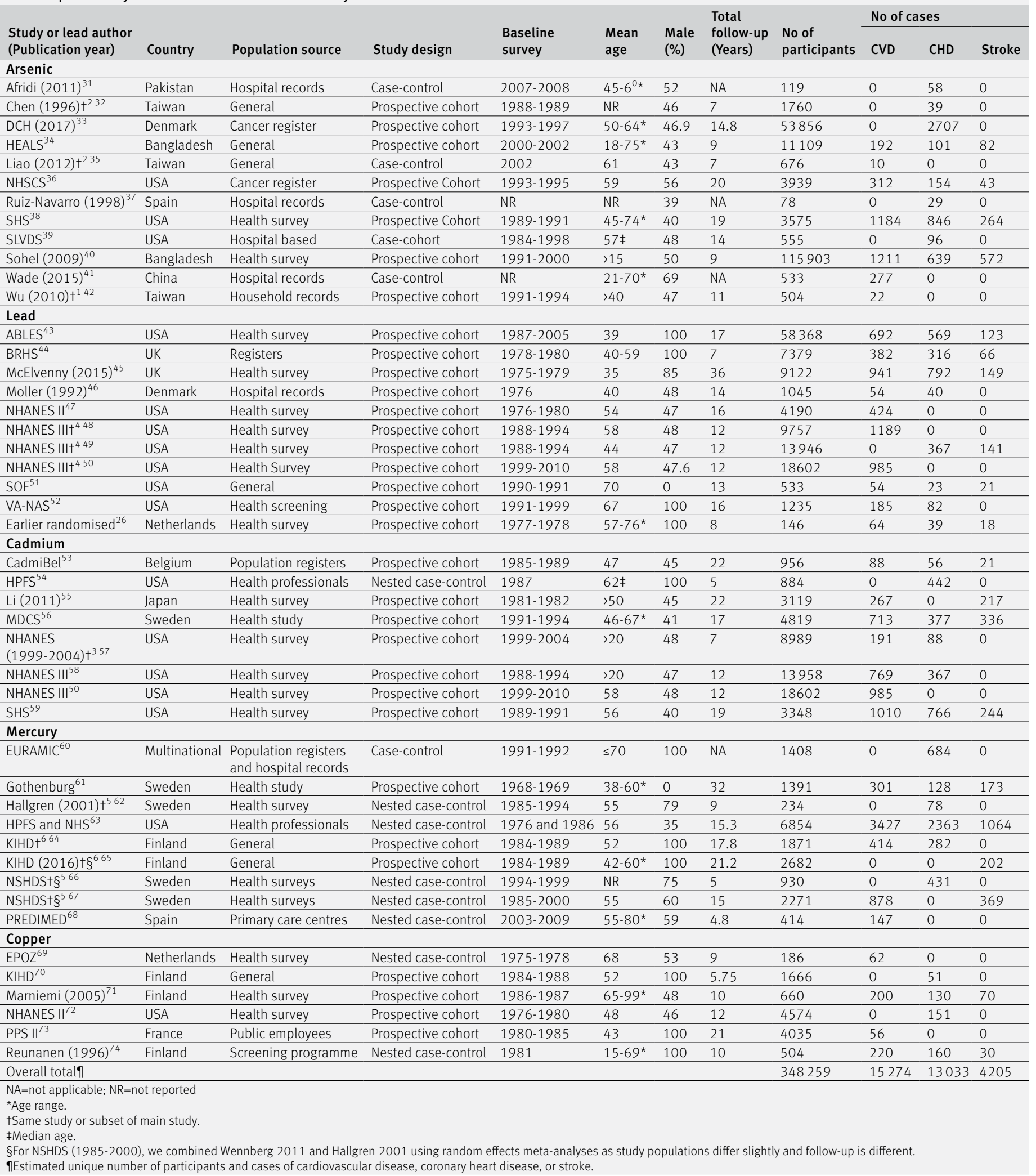

interval 1.04 to $1.63 ; 1.43,1.16$ to $1.76 ; 1.33,1.09$ to 1.64; and $1.81,1.05$ to 3.11). There was no evidence of an association of mercury levels with the risk of cardiovascular disease $(0.94,0.66$ to 1.36$)$. However, there was significant evidence of heterogeneity in cardiovascular disease estimates across studies $\left(\mathrm{I}^{2}\right.$ ranging from $68 \%, \mathrm{P}=0.001$ for lead to $84 \%, \mathrm{P}<0.001$ for mercury).

Lead and cadmium were also associated with a significantly increased risk of stroke (respective relative 


\begin{tabular}{|c|c|c|c|c|}
\hline Author, year (Pubmed ID) & $\begin{array}{l}\text { Selection } \\
(\operatorname{Max}=4)\end{array}$ & $\begin{array}{l}\text { Comparability } \\
(\operatorname{Max}=2)\end{array}$ & $\begin{array}{l}\text { Outcome } \\
(\operatorname{Max}=3)\end{array}$ & $\begin{array}{l}\text { Overall quality } \\
\text { score }(\operatorname{Max}=9)\end{array}$ \\
\hline Aoki, 2016 (26735529) & 3 & 2 & 3 & 8 \\
\hline Barregard, 2015 (26517380) & 3 & 2 & 3 & 8 \\
\hline Bergdahl, $2013(22350276)^{\star}$ & 2 & 2 & 3 & 7 \\
\hline Chen, 2011 (21546419) & 3 & 2 & 3 & 8 \\
\hline Chen, 1996 (8624771) & 1 & 2 & 3 & 6 \\
\hline Chowdhury, 2014 (24769120) & 1 & 1 & 3 & 5 \\
\hline Daneshmand. 2016 (26991769)* & 3 & 2 & 3 & 8 \\
\hline Farzan, $2015(26048586)$ & 2 & 2 & 3 & 7 \\
\hline Ford, 2000 (10905530) & 4 & 2 & 3 & 9 \\
\hline Khalil, 2009 (19344498) & 2 & 2 & 3 & 7 \\
\hline Kromhout 1988, (3203644) & 3 & 2 & 1 & 7 \\
\hline Leone, 2006 (16570028) & 2 & 2 & 2 & 6 \\
\hline Li, $2011(22340168)^{\star}$ & 3 & 1 & 3 & 7 \\
\hline Liao, 2012 (22569360) & 1 & 2 & 2 & 5 \\
\hline Lustberg, 2002 (12437403) & 3 & 2 & 3 & 8 \\
\hline Marniemi, 2005 (15955467) & 3 & 2 & 2 & 7 \\
\hline McElvenny, 2015 (25872777) & 2 & 1 & 2 & 5 \\
\hline Menke 2006, (16982939) & 3 & 2 & 3 & 8 \\
\hline Menke, 2009 (19270787) & 4 & 2 & 3 & 9 \\
\hline Moller, 1992 (1462969) & 4 & 2 & 1 & 7 \\
\hline Monrad, 2017 (28157645) & 2 & 2 & 2 & 6 \\
\hline Moon, 2013 (24061511) & 3 & 2 & 3 & 8 \\
\hline Nawrot, 2008 (19079711) & 3 & 2 & 3 & 8 \\
\hline Pocock, 1988 (3203640) & 3 & 1 & 3 & 7 \\
\hline Salonen, 1991 (1877585) & 3 & 2 & 2 & 7 \\
\hline Schober, 2006 (17035139) & 3 & 2 & 2 & 7 \\
\hline Sohel, 2009 (19797964) & 2 & 1 & 1 & 4 \\
\hline Tellez-Plaza, 2013 (23514838) & 3 & 2 & 3 & 8 \\
\hline Tellez-Plaza, 2012 (22472185) & 3 & 2 & 1 & 6 \\
\hline Virtanen, 2005 (15539625) & 4 & 2 & 3 & 9 \\
\hline Weisskopf, 2009 (19738141) & 2 & 2 & 2 & 6 \\
\hline Wu, $2010(20708634)$ & 1 & 2 & 3 & 6 \\
\hline
\end{tabular}

risks of $1.63,95 \%$ confidence interval 1.14 to 2.34 and $1.72,1.29$ to 2.28 ) with no evidence of heterogeneity across studies $\left(\mathrm{I}^{2}=0 \%, \mathrm{P}=0.76\right.$ and $\left.\mathrm{I}^{2}=10 \%, \mathrm{P}=0.33\right)$. There was no evidence of an association of arsenic with risk of stroke, with little to no evidence of heterogeneity in stroke estimates across studies for either contaminant $\left(\mathrm{I}^{2}=56 \%, \mathrm{P}=0.08\right)$.

\section{Dose-response meta-analyses}

The dose-response relations between levels of toxic metals and cardiovascular outcomes, based on

\begin{tabular}{|c|c|c|c|c|}
\hline Author, year (Pubmed ID) & $\begin{array}{l}\text { Selection } \\
(\operatorname{Max}=4)\end{array}$ & $\begin{array}{l}\text { Comparability } \\
(\operatorname{Max}=2)\end{array}$ & $\begin{array}{l}\text { Exposure } \\
(\operatorname{Max}=3)\end{array}$ & $\begin{array}{l}\text { Overall quality } \\
\text { score }(\operatorname{Max}=9)\end{array}$ \\
\hline Afridi, 2011 (20480400) & 4 & 1 & 2 & 7 \\
\hline Downer, 2016 (28056794) & 4 & 2 & 3 & 9 \\
\hline Guallar, 2005 (11570992) & 2 & 2 & 2 & 6 \\
\hline Hallgren, 2001 (11572934) & 3 & 2 & 3 & 8 \\
\hline James, 2015 (25350952) & 4 & 2 & 2 & 8 \\
\hline Kok, 1988 (3394701) & 3 & 2 & 3 & 8 \\
\hline Mozaffarian, 2011 (21428767) & 3 & 2 & 3 & 8 \\
\hline Reunanen, 1996 (8862478) & 2 & 2 & 3 & 7 \\
\hline Ruiz-Navarro, 1998 (9618928)* & 1 & 1 & 2 & 4 \\
\hline Wade, 2015 (25889926) & 2 & 2 & 2 & 7 \\
\hline \$Wennberg, 2007 (17537290)* & 4 & 2 & 3 & 9 \\
\hline Wennberg, 2011 (21048056) & 4 & 2 & 3 & 9 \\
\hline Yoshizawa, 2002 (12456851)* & 4 & 2 & 3 & 9 \\
\hline
\end{tabular}

available relevant data are shown in supplementary materials, figure S1. Only two studies reporting on exposure to arsenic in drinking water, three studies reporting on exposure to cadmium, and four studies reporting on exposure to lead, provided sufficient information to perform the dose-response analysis. In summary, for baseline arsenic levels in well water and risk of cardiovascular disease, there was evidence of a linear association across the full spectrum of arsenic levels $(0 \mu \mathrm{g} / \mathrm{L}$ to $369.5 \mu \mathrm{g} / \mathrm{L}, \mathrm{P}=0.31$ for nonlinearity; see supplementary material, fig S1A). Similarly, there was evidence of a linear association between lead levels in blood and the risk of coronary heart disease $(\mathrm{P}=0.677$ for nonlinearity; see supplementary material, fig S1B), with a pooled relative risk for risk of coronary heart disease per $5 \mu \mathrm{g} / \mathrm{dL}$ increment in lead levels being 1.07 (95\% confidence interval 1.04 to 1.10). By contrast, for the association between cadmium levels in urine and the risk of cardiovascular disease, an initial steep increase in risk (within urine cadmium levels of $0.11 \mu \mathrm{g} / \mathrm{g}$ to $1.41 \mu \mathrm{g} / \mathrm{g}$ ) was followed by a weaker increase in risk beyond 1.41 $\mu \mathrm{g} / \mathrm{g}$. The relative risk of cardiovascular disease for each $0.75 \mu \mathrm{g} / \mathrm{g}$ increment of cadmium was 1.21 (95\% confidence interval 1.09 to $1.33, \mathrm{P}=0.656$ for nonlinearity; see supplementary materials, fig S1C). There was a significant linear association between cadmium levels in urine and the risk of coronary heart disease $(\mathrm{P}=0.865$ for nonlinearity; see supplementary materials, fig S1D).

\section{Subgroup analyses and assessment of publication bias}

Little of the variation in risk estimates across contaminants was explained by any of the recorded study level characteristics ( $\mathrm{P}>0.05$ for most factors investigated; see supplementary materials, fig S2S6). For example, there was no significant difference in relative risks for cardiovascular disease across the types of individual exposures (eg, blood $v$ other measurement sources; $\mathrm{P}>0.05$ ). Additionally, pooled relative risks were all generally similar regardless of the level of adjustment for possible confounding factors considered in the included studies, by geographical location, baseline health, or size of the studies. In analyses investigating the effect of arsenic measurement source (urine and toenails $v$ water) on risk estimates of cardiovascular disease, coronary heart disease, and stroke, risk estimates were comparable between studies with no evidence of significant heterogeneity between studies measuring arsenic in drinking water versus biomarkers (see supplementary materials, fig S7). Subgroup analyses comparing the risk of cardiovascular disease, coronary heart disease, and stroke in never-smokers compared to current and former smokers produced similar results for arsenic and cadmium exposure (see supplementary materials, fig S8 and S9). Funnel plots (see supplementary materials, fig S10-S14) and tests for publication bias for other markers and outcomes were non-significant for most contaminants $(\mathrm{P}>0.05)$, however, there was 


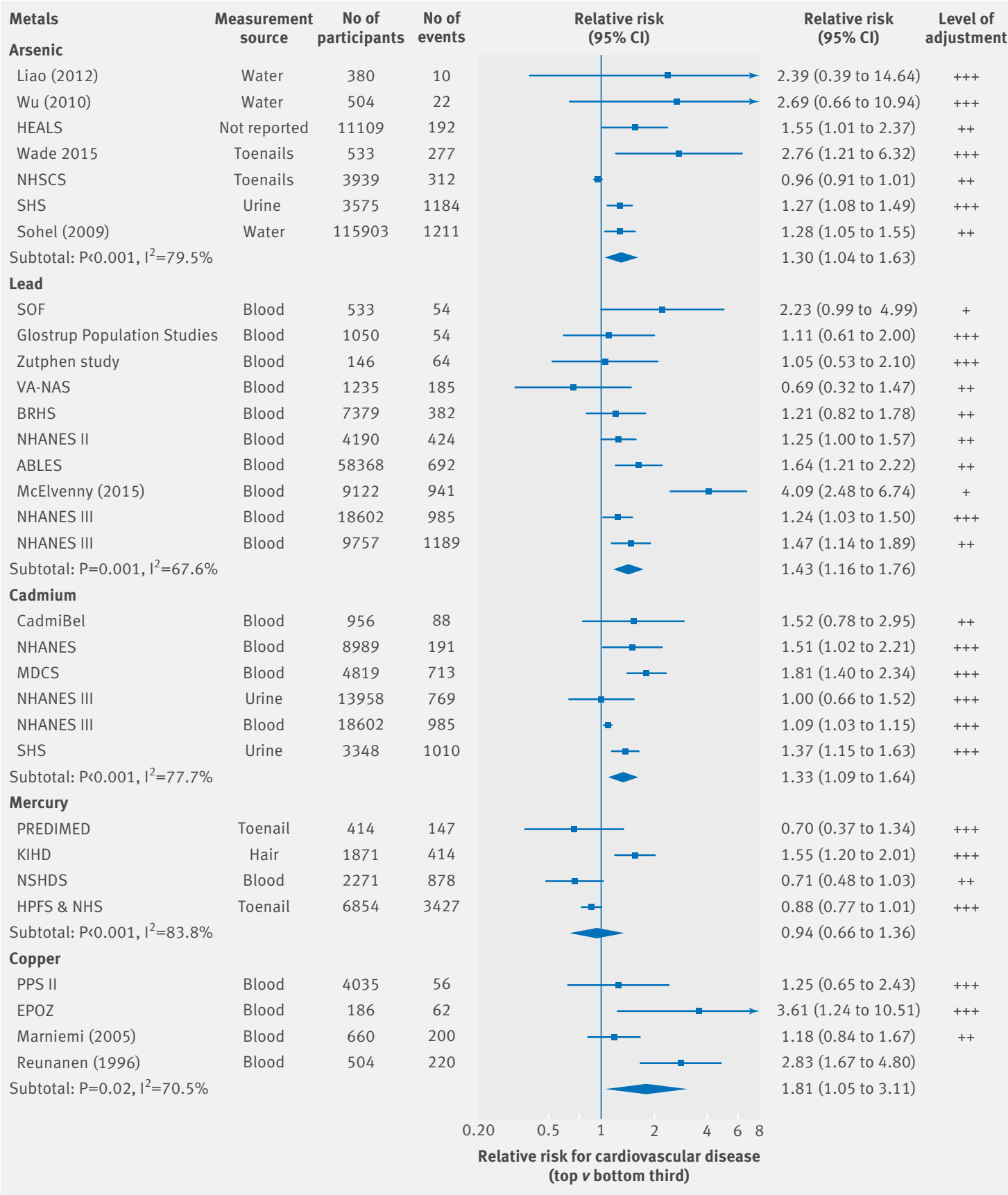

Fig 3 | Association between environmental contaminants and cardiovascular disease. $N R=$ not reported; +=minimally adjusted (typically adjusted for age and sex only); ++=adjusted for at least one non blood based cardiovascular risk factor (eg, systolic blood pressure, body mass index, history of diabetes, etc); +++=additionally adjusted for at least one blood based cardiovascular risk factor (eg, total cholesterol, c-reactive protein, etc)

evidence of publication bias for studies reporting on arsenic association with cardiovascular disease $(\mathrm{P}=0.01)$ and coronary heart disease $(\mathrm{P}<0.001)$ (see supplementary materials, table S5). ${ }^{75}$

\section{Discussion}

\section{Principal findings}

We have conducted a systematic review and meta-analysis, using non-overlapping data from approximately 350000 participants from 37 studies, to help clarify available evidence on the associations of environmental toxic elements with the risk of cardiovascular disease. Overall, our results indicate that exposures to arsenic, lead, cadmium, and copper are each positively and importantly associated with cardiovascular disease and coronary heart disease, cardiovascular disease and stroke, or all cardiovascular outcomes. By contrast, mercury was not significantly associated with cardiovascular risk. Additionally, based on relevant available data, the shape of associations for levels of arsenic, lead, and cadmium with cardiovascular outcomes was approximately linear. 


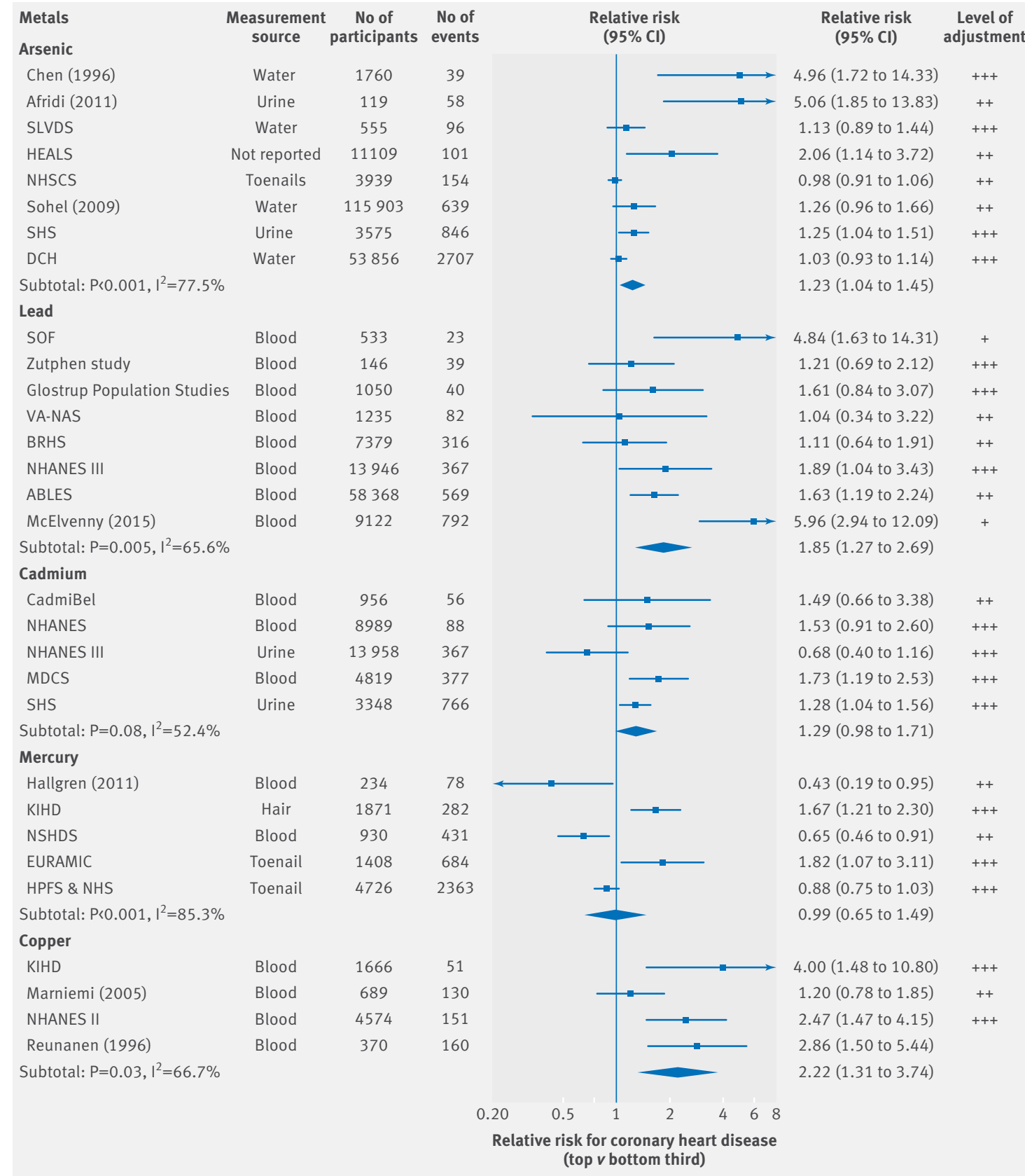

Fig 4 | Association between environmental contaminants and coronary heart disease. $N R=$ not reported; $+=$ minimally adjusted (typically adjusted for age and sex only); ++=adjusted for at least one non blood based cardiovascular risk factor (eg, systolic blood pressure, body mass index, history of diabetes, etc); +++=additionally adjusted for at least one blood based cardiovascular risk factor (eg, total cholesterol, c-reactive protein, etc)

\section{Comparison with other studies}

Findings observed in this review may have several potential explanations. We found a positive association of arsenic, an environmental toxic metal found in large quantities in rice and groundwater in many parts of the world, with the risk of coronary heart disease. ${ }^{76}$ 77 Arsenic exposure has been reported to accelerate and exacerbate atherosclerosis in apolipoprotein E-knockout mice. ${ }^{78}$ Clinical and experimental studies of arsenic exposure have reported the production of reactive oxygen species in endothelial cells, ${ }^{80}$ up regulation of inflammatory signals, ${ }^{81}$ and higher blood pressure. ${ }^{82-84}$ These findings extend several previous epidemiological studies that reported striking associations with Blackfoot disease (a severe peripheral vascular disease) in people exposed to extremely high cumulative doses of arsenic. ${ }^{85} 86$

Although circulating levels of lead seem to be in decline in the developed world, ${ }^{87}$ owing principally to the concomitant decrease in the usage of leaded gasoline and leaded paint, lead exposure remains considerably high in many areas. $^{58}$ The strong positive association found in our review between lead and the risk of cardiovascular disease, reinforces lead 


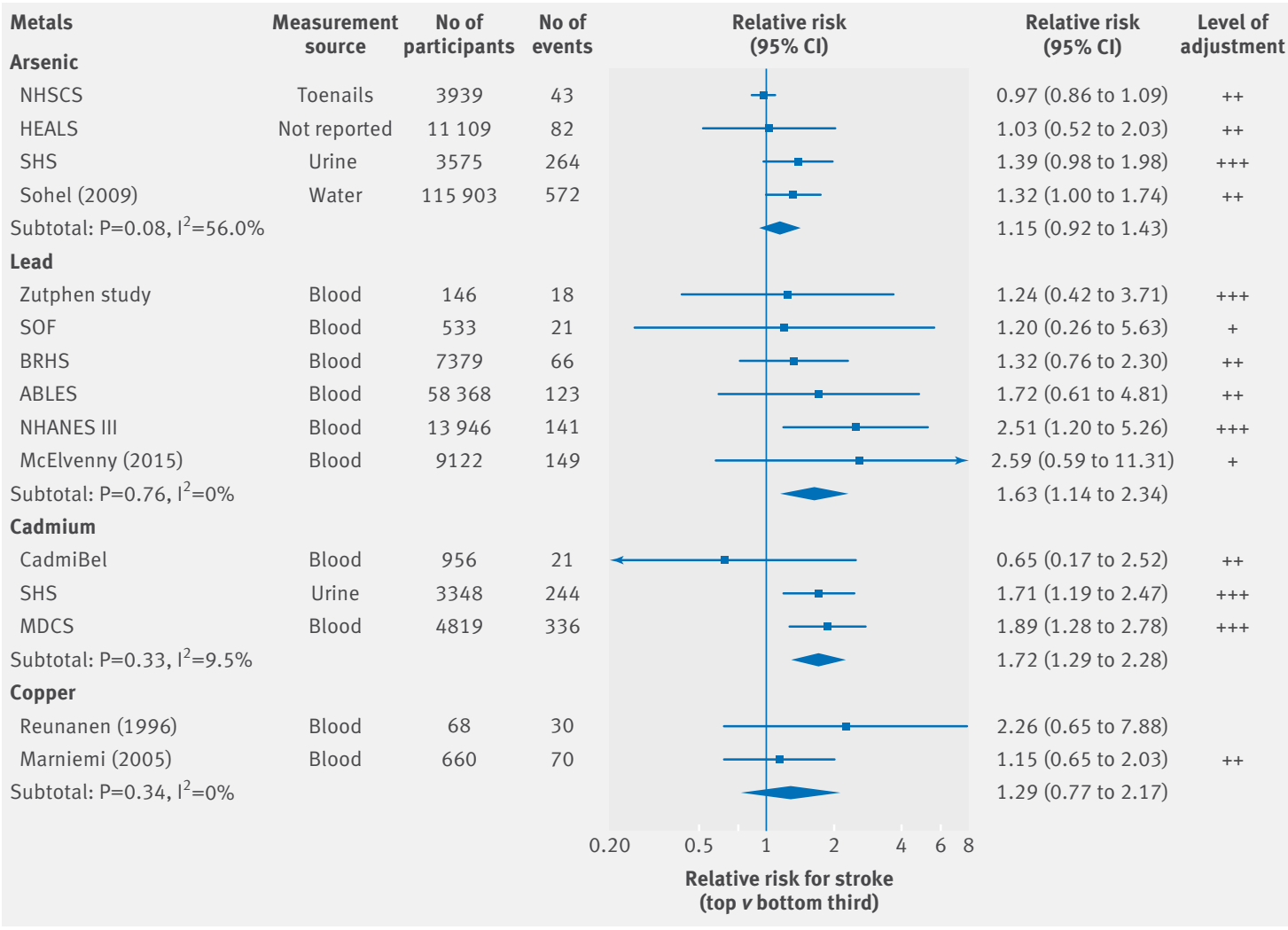

Fig 5 | Association between environmental contaminants and stroke. $N R=$ not reported; +=minimally adjusted (typically adjusted for age and sex only); ++=adjusted for at least one non blood based cardiovascular risk factor (eg, systolic blood pressure, body mass index, history of diabetes etc); +++=additionally adjusted for at least one blood based cardiovascular risk factor (eg, total cholesterol, c-reactive protein, etc)

exposure as a major public health concern. ${ }^{89}$ Two key pathways by which lead has been implicated in the risk of cardiovascular disease are mediation through accelerated systolic blood pressure and damage to renal function. ${ }^{90}$ Previous studies have also suggested an association of lead with atherosclerosis as a result of lead-induced oxidative stress and inflammation after exposure. ${ }^{11} 15$

The present review also shows a positive association of copper with cardiovascular disease, as suggested in previous studies. ${ }^{9192}$ While copper is an essential trace element, excess copper can induce oxidative stress by generation of reactive oxygen species. ${ }^{11}$ Coppermediated lipid peroxidation has been demonstrated in several in vivo and in vitro studies. ${ }^{21}$ Another possible mechanism for the potential deleterious effects of copper is through a copper-homocystein complex which have been suggested to induce endothelial dysfunction and vascular injury. ${ }^{93}$ For both arsenic and copper, albeit based on limited data, the potentially linear dose-response relation that we have observed indicates that even at lower average exposure levels (common in many global regions), these toxic metals may have a detrimental impact on vascular health.

We also observed a positive association between levels of cadmium and cardiovascular disease, which was independent of several potential risk of cardiovascular disease factors (including smoking status). Cadmium's adverse effects on the vascular system are thought to be mediated by oxidative stress, inflammation, and endothelial cell damage, which can result in atherosclerosis. This is important as cadmium is widely prevalent in groundwater and common plantbased foods (eg, rice and vegetables)..$^{94}$

Conversely, mercury, a potentially toxic trace metal that humans are exposed to primarily through fish consumption, ${ }^{95}$ was not significantly associated with the risk of cardiovascular disease in the current review. Although some individual studies have observed inverse relations between mercury levels and the risk of cardiovascular disease, ${ }^{62}{ }^{66}$ there is currently no accepted biological explanation that supports such a link. ${ }^{66}$

\section{Strengths and limitations of the study}

Strengths and limitations of this work merit careful consideration. This is the first comprehensive metaanalysis of several key environmental toxic metals in relation to the risk of cardiovascular disease. We have focused solely on individual-level assessments of exposure to toxic metals, and performed our analyses based primarily on toxic metals measured directly using an objective biomarker or well established measures of individual level exposure such as arsenic in drinking water. However, it should be noted that the biological determinants, precision of measurements and 
ability to reflect long term exposure may differ across various biomarkers. ${ }^{96}$ Therefore, to ensure consistent long term exposure assessment, the use of repeated measurements over time that accounts for any potential individual variation in levels (ie, regression dilution) ${ }^{97}$ should be considered in future studies. ${ }^{55}$ Furthermore, most studies that measured arsenic and cadmium levels in urine were based on spot or first morning void samples, which might be limited by the fact that they reflect the hydration status of the individual at the time of collection, and therefore, may differ markedly in dilution owing to differences in urinary flow rate, ${ }^{98}$ and differences in stability and reproducibility of metals measured in them. Additionally, although over half the risk estimates for urinary arsenic and cadmium from all included studies were creatinine adjusted, some were unadjusted for any marker of urinary dilution. While this review is limited to published findings, the use of individual participant data, in future largescale primary studies, would allow a more detailed and specific assessment of the association between the considered environmental toxic metals and cardiovascular disease, including: assessing the role of routes of exposure (eg, environmental $v$ occupational); a standardised adjustment for confounders (eg, smoking status); reduce heterogeneity resulting from meta-analysis of diverse study populations; and a more consistent characterisation of any potential dose-response relation. Such comprehensive assessments are currently underway. ${ }^{99} 100$ Equally, our review was solely based on observational data which might be affected by unmeasured confounders - making a causal inference difficult. In this regard, an earlier randomised trial, based on people with pre-existing cardiovascular disease, suggested that moderate reduction of cardiovascular events occured after intravenous chelation therapy (which facilitates urinary excretion of heavy metals) ${ }^{101}$ compared with placebo. However, further conclusive trials, especially those involving general populations, are needed. Additionally, the identification of polymorphisms influencing circulating levels of these toxic metals which can be used as proxies for circulating levels (such as polymorphisms near AS3MT, MT1A/B), ${ }^{102-104}$ may also allow future investigations of potential causal associations with disease using instrumental variable analysis (ie, mendelian randomisation analyses). ${ }^{105}$

\section{Implications for clinicians and policy makers}

Our findings may have important policy and scientific implications. Firstly, these findings highlight the importance of environmental toxic metals in enhancing cardiovascular risk, beyond the roles of conventional behavioural risk factors (such as tobacco use and unhealthy diet). These results may have a key policy implication given that current global noncommunicable disease prevention strategies (eg, WHO 2018 Report $)^{106}$ are focused primarily on tackling behavioural determinants. Recognising environmental factors (such as toxic metals) as additional priorities, therefore, will help gain wider sociopolitical support for setting up appropriate legislation, preventive strategies and standards, and investment to tackle these major global determinants of cardiovascular diseases. Secondly, the observed associations appeared approximately linear for arsenic, lead, and cadmium levels with cardiovascular disease outcomes, indicating the risk of adverse health consequences even at a relatively low exposure of these toxic metals. Nonetheless, these current findings warrant further detailed research to reliably quantify suboptimal levels to define individuals at risk and to trigger appropriate clinical action. Presently, in clinical practice, toxicity for these metals, if suspected, are established through a range of diagnostic investigations including blood and 24-hour urinary analyses and typically involving an inductively coupled plasma mass spectrometry analytical technique for elemental determinations. ${ }^{107}$ Treatment options for heavy metal toxicity include various antidotes and chelating agents (which enhance the elimination of metals from the body) such as succimer (DMSA), unithiol (DMPS), sodium calcium edetate, and dimercaprol. ${ }^{108}$ However, since efficacy and response of these therapies vary greatly, ${ }^{109}$ primary prevention, by developing evidence based public health guidelines and innovative low cost, scalable interventions to reduce human exposure to these contaminants, should be prioritised.

\section{Conclusion}

Results of this meta-analysis indicate that exposure to arsenic, lead, cadmium, and copper is associated with an increased risk of cardiovascular disease and coronary heart disease. By contrast, mercury was not associated with cardiovascular risk. These findings reinforce the (often under-recognised) importance of environmental toxic metals in cardiovascular risk, beyond the roles of conventional behavioural risk factors. Further detailed work, however, to better characterise these associations and to assess causality, is needed.

\section{AUTHOR AFFILIATIONS}

${ }^{1}$ Department of Public Health and Primary Care, University of Cambridge, Strangeways Research Laboratory, Cambridge CB1 8RN, UK ${ }^{2}$ MRC Integrative Epidemiology Unit, University of Bristol, Bristol, UK ${ }^{3}$ Bristol Population Health Science Institute, Bristol Medical School, Bristol, UK

${ }^{4}$ National Institute for Health Research Bristol Biomedical Research Centre, Bristol, UK

${ }^{5}$ University Hospitals Bristol NHS Foundation Trust, Bristol, UK

${ }^{6}$ Translational Health Sciences, Bristol Medical School,

Musculoskeletal Research Unit, University of Bristol, Bristol, UK

${ }^{7}$ Institute of Social and Preventive Medicine, Bern, Switzerland

${ }^{8}$ Department of Medical Statistics, London School of Hygiene and

Tropical Medicine, London, UK

${ }^{9}$ Department of Neurology, Medical University of Innsbruck, Innsbruck, Austria

${ }^{10}$ Emory University, Atlanta, Georgia, USA

${ }^{11}$ University of Guyana, Georgetown, Guyana

${ }^{12}$ National Institute for Health Research Blood and Transplant Research Unit in Donor Health and Genomics, Department of Public Health and Primary Care, University of Cambridge, Cambridge, UK

${ }^{13} \mathrm{NHS}$ Blood and Transplant, Cambridge, UK 
Contributors: RC and ED designed the study. AR, LMO, SS, SKK, RC, and ED acquired, analysed, and interpreted the data. RC, AR, SS, and ED drafted the manuscript. AR and SKK performed the statistical analysis. RC and ED supervised the study. All authors had full access to the data in the study and can take responsibility for the integrity of the data and the accuracy of the data analysis. RC is the guarantor. Funding: This work was not supported by any external grants or funding.

Competing interests: All authors have completed the ICMJE uniform disclosure form at www.icmje.org/coi_disclosure.pdf and declare: no support from any organisation for the submitted work; no financial relationships with any organisations that might have an interest in the submitted work in the previous three years; no other relationships or activities that could appear to have influenced the submitted work. $\mathrm{RC}$ is the Co-Principal Investigator for the UK Research Council UK's f8.1M CAPABLE Global Health Programme, which is investigating the roles of toxic metals and air pollutants on future noncommunicable disease outcomes in Bangladesh and elsewhere.

Ethical approval: Not required.

Data sharing: Dataset is available from the corresponding author.

Transparency: The manuscripts guarantor (RC) affirms that the manuscript is an honest, accurate, and transparent account of the study being reported; that no important aspects of the study have been omitted; and that any discrepancies from the study as planned have been explained.

This is an Open Access article distributed in accordance with the Creative Commons Attribution Non Commercial (CC BY-NC 4.0) license, which permits others to distribute, remix, adapt, build upon this work non-commercially, and license their derivative works on different terms, provided the original work is properly cited and the use is noncommercial. See: http://creativecommons.org/licenses/by-nc/4.0/

1 Blacksmith Institute, Green Cross. The world's worst pollution problems: assessing health risks at hazardous waste sites. http:// www.worstpolluted.org/files/FileUpload/files/WWPP_2012.pdf

2 Caine ED. Health risks from toxic pollution. Lancet 2012;380:1532. doi:10.1016/S0140-6736(12)61862-5

3 Fawell J, Nieuwenhuiijsen MJ. Contaminants in drinking water. Br Med Bull 2003;68:199-208. doi:10.1093/bmb/ldg027

4 World Health Organization. Preventing noncommunicable diseases (NCDs) by reducing environmental risk factors. http://apps.who.int/ iris/bitstream/handle/10665/258796/WHO-FWC-EPE-17.01-eng. pdf;jsessionid=7368E2B81AC7C9CE8B40C38C7EED1F9E? sequence $=1$

5 Järup L. Hazards of heavy metal contamination. $\mathrm{Br}$ Med Bull 2003;68:167-82. doi:10.1093/bmb/ldg032

6 Straif K, Benbrahim-Tallaa L, Baan R, et al, WHO International Agency for Research on Cancer Monograph Working Group. A review of human carcinogens--Part C: metals, arsenic, dusts, and fibres. Lancet Oncol 2009;10:453-4. doi:10.1016/S14702045(09)70134-2

7 D’Ippoliti D, Santelli E, De Sario M, Scortichini M, Davoli M, Michelozzi P. Arsenic in Drinking Water and Mortality for Cancer and Chronic Diseases in Central Italy, 1990-2010. PLoS One 2015;10:e0138182. doi:10.1371/ journal.pone.0138182

8 Li Z, Ma Z, van der Kuijp TJ, Yuan Z, Huang L. A review of soil heavy metal pollution from mines in China: pollution and health risk assessment. Sci Total Environ 2014;468-469:843-53. doi:10.1016/j.scitotenv.2013.08.090

9 IARC. IARC monographs on the evaluation of carcinogenic risks to humans. Arsenic, Metals, Fibres and Dusts. IARC, 2012

10 Jomova K, Jenisova Z, Feszterova M, et al. Arsenic: toxicity, oxidative stress and human disease. J Appl Toxicol 2011;31:95-107.

11 Jomova K, Valko M. Advances in metal-induced oxidative stress and human disease. Toxicology 2011;283:65-87. doi:10.1016/j. tox.2011.03.001

12 Tsuji JS, Perez V, Garry MR, Alexander DD. Association of low-level arsenic exposure in drinking water with cardiovascular disease: a systematic review and risk assessment. Toxicology 2014;323:78-94. doi:10.1016/j.tox.2014.06.008

13 Moon K, Guallar E, Navas-Acien A. Arsenic exposure and cardiovascular disease: an updated systematic review. Curr Atheroscler Rep 2012;14:542-55. doi:10.1007/s11883-0120280-x

14 Tellez-Plaza M, Jones MR, Dominguez-Lucas A, Guallar E, NavasAcien A. Cadmium exposure and clinical cardiovascular disease: a systematic review. Curr Atheroscler Rep 2013;15:356. doi:10.1007/ s11883-013-0356-2
15 Navas-Acien A, Guallar E, Silbergeld EK, Rothenberg SJ. Lead exposure and cardiovascular disease--a systematic review. Environ Health Perspect 2007;115:472-82. doi:10.1289/ehp.9785

16 Moon KA, Oberoi S, Barchowsky A, et al. A dose-response meta-analysis of chronic arsenic exposure and incident cardiovascular disease Int J Epidemiol 2017:46:1924-39. doi:10.1093/ije/dyx202

17 Navas-Acien A, Sharrett AR, Silbergeld EK, et al. Arsenic exposure and cardiovascular disease: a systematic review of the epidemiologic evidence. Am J Epidemiol 2005;162:1037-49. doi:10.1093/aje/ kwi330

18 World Health Organization. Top ten chemicals of major public health concern. http://www.who.int/ipcs/assessment/public_health/ chemicals_phc/en/

19 Bhatnagar A. Environmental cardiology: studying mechanistic links between pollution and heart disease. Circ Res 2006;99:692-705. doi:10.1161/01.RES.0000243586.99701.cf

20 Nakano E, Williamson MP, Williams NH, Powers HJ. Copper-mediated LDL oxidation by homocysteine and related compounds depends largely on copper ligation. Biochim Biophys Acta 2004;1688:33-42. doi:10.1016/j.bbadis.2003.10.005

21 Gaetke LM, Chow CK. Copper toxicity, oxidative stress, and antioxidant nutrients. Toxicology 2003;189:147-63. doi:10.1016/ 50300-483X(03)00159-8

22 Jain VK, Mohan G. Serum zinc and copper in myocardial infarction with particular reference to prognosis. Biol Trace Elem Res 1991;31:317-22. doi:10.1007/BF02990200

23 Niskanen J, Marniemi J, Piironen O, et al. Trace element levels in serum and urine of subjects died of coronary heart disease. Acta Pharmacol Toxicol (Copenh) 1986;59(Suppl 7):340-3. doi:10.1111/j.1600-0773.1986.tb02775.x

24 Wells GA, Shea B, O'connell D, et al. The Newcastle-Ottawa Scale (NOS) for assessing the quality of nonrandomised studies in metaanalyses. Ottawa Hospital Research Institute, 2011.

25 Chêne G, Thompson SG. Methods for summarizing the risk associations of quantitative variables in epidemiologic studies in a consistent form. Am J Epidemiol 1996;144:610-21. doi:10.1093/ oxfordjournals.aje.a008971

26 Kromhout D. Blood lead and coronary heart disease risk among elderly men in Zutphen, The Netherlands. Environ Health Perspect 1988;78:43-6. doi:10.1289/ehp.887843

27 Higgins JP, Thompson SG, Deeks JJ, Altman DG. Measuring inconsistency in meta-analyses. BMJ 2003;327:557-60. doi:10.1136/bmj.327.7414.557

28 Egger M, Davey Smith G, Schneider M, Minder C. Bias in metaanalysis detected by a simple, graphical test. BMJ 1997;315:629-34 doi:10.1136/bmj.315.7109.629

29 Greenland S, Longnecker MP. Methods for trend estimation from summarized dose-response data, with applications to meta-analysis. Am J Epidemiol 1992;135:1301-9. doi:10.1093/oxfordjournals.aje. a116237

30 Harrell FEIr, Lee KL, Pollock BG. Regression models in clinical studies: determining relationships between predictors and response. J Natl Cancer Inst 1988;80:1198-202. doi:10.1093/jnci/80.15.1198

31 Afridi HI, Kazi TG, Kazi N et al. Association of environmental toxic elements in biological samples of myocardial infarction patients at different stages. Biol Trace Elem Res 2011;141:26-40. doi:10.1007/ s12011-010-8713-2

32 Chen CJ, Chiou HY, Chiang MH, et al. Dose-Response relationship between Ischemic Heart Disease mortality and long-term Arsenic exposure. Arterioscler Thromb Vasc Biol 1996;16(4):504-10.

33 Monrad M, Ersbøll AK, Sørensen M, et al. Low-level arsenic in drinking water and risk of incident myocardial infarction: A cohort study. Environ Res 2017;154:318-24. doi:10.1016/j. envres.2017.01.028

34 Chen Y, Graziano JH, Parvez F, et al. Arsenic exposure from drinking water and mortality from cardiovascular disease in Bangladesh: prospective cohort study. BMJ 2011;342:d2431. doi:10.1136/bmj. d2431

35 Liao YT, Chen Cl, Li WF, et al. Elevated lactate dehydrogenase activity and increased cardiovascular mortality in the arsenic-endemic areas of southwestern Taiwan. Toxicol Appl Pharmacol 2012;262:232-7. doi:10.1016/j.taap.2012.04.028

36 Farzan SF, Chen Y, Rees JR, Zens MS, Karagas MR. Risk of death from cardiovascular disease associated with low-level arsenic exposure among long-term smokers in a US population-based study. Toxicol Appl Pharmacol 2015;287:93-7. doi:10.1016/j.taap.2015.05.013

37 Ruiz-Navarro ML, Navarro-Alarcón M, Lopez González-de la Serrana H, Pérez-Valero V, López-Martinez MC. Urine arsenic concentrations in healthy adults as indicators of environmental contamination: relation with some pathologies. Sci Total Environ 1998;216:55-61. doi:10.1016/S0048-9697(98)00136-3

38 Moon KA, Guallar E, Umans IG, et al. Association between exposure to low to moderate arsenic levels and incident 
cardiovascular disease. A prospective cohort study. Ann Intern Med 2013;159:649-59.

39 James KA, Byers T, Hokanson JE, Meliker JR, Zerbe GO, Marshall JA. Association between lifetime exposure to inorganic arsenic in drinking water and coronary heart disease in Colorado residents. Environ Health Perspect 2015;123:128-34. doi:10.1289/ ehp.1509791R

40 Sohel N, Persson LA, Rahman M, et al. Arsenic in drinking water and adult mortality: a population-based cohort study in rural Bangladesh. Epidemiology 2009;20:824-30. doi:10.1097/ EDE.0b013e3181bb56ec

41 Wade TJ, Xia Y, Mumford J, et al. Cardiovascular disease and arsenic exposure in Inner Mongolia, China: a case control study. Environ Health 2015;12;14-35. doi:10.1186/s12940-015-0022-y.

42 Wu MM, Chiou HY, Chen CL, et al. GT-repeat polymorphism in the heme oxygenase-1 gene promoter is associated with cardiovascular mortality risk in an arsenic-exposed population in northeastern Taiwan. Toxicol Appl Pharmacol 2010;248:226-33. doi:10.1016/j. taap.2010.08.005

43 Chowdhury R, Sarnat SE, Darrow L, McClellan W, Steenland K. Mortality among participants in a lead surveillance program. Environ Res 2014:132:100-4. doi:10.1016/i.envres.2014.03.008

44 Pocock SI, Shaper AG, Ashby D, Delves HT, Clayton BE. The relationship between blood lead, blood pressure, stroke, and heart attacks in middle-aged British men. Environ Health Perspect 1988:78:23-30. doi:10.1289/ehp.887823

45 McElvenny DM, Miller BG, MacCalman LA, et al. Mortality of a cohort of workers in Great Britain with blood lead measurements. Occup Environ Med 2015;72:625-32. doi:10.1136/oemed-2014-102637

46 Møller L, Kristensen TS. Blood lead as a cardiovascular risk factor. Am J Epidemiol 1992;136:1091-100. doi:10.1093/oxfordjournals.aje. a116574

47 Lustberg M, Silbergeld E. Blood lead levels and mortality. Arch Intern Med 2002;162:2443-9. doi:10.1001/archinte.162.21.2443

48 Schober SE, Mirel LB, Graubard BI, Brody DJ, Flegal KM. Blood lead levels and death from all causes, cardiovascular disease, and cancer: results from the NHANES III mortality study. Environ Health Perspect 2006;114:1538-41.

49 Menke A, Muntner P, Batuman V, Silbergeld EK, Guallar E. Blood lead below 0.48 micromol/L (10 microg/dL) and mortality among US adults. Circulation 2006;114:1388-94. doi:10.1161/ CIRCULATIONAHA.106.628321

50 Aoki Y, Brody DJ, Flegal KM, Fakhouri TH, Axelrad DA, Parker JD. Blood Lead and Other Metal Biomarkers as Risk Factors for Cardiovascular Disease Mortality. Medicine (Baltimore) 2016;95:e2223. doi:10.1097/MD.0000000000002223

51 Khalil N, Wilson JW, Talbott EO, et al. Association of blood lead concentrations with mortality in older women: a prospective cohort study. Environmental Health 2009;8:15. doi:10.1186/1476069X-8-15

52 Weisskopf MG, Jain N, Nie H, et al. A prospective study of bone lead concentration and death from all causes, cardiovascular diseases, and cancer in the Department of Veterans Affairs Normative Aging Study. Circulation 2009;120:1056-64. doi:10.1161/ CIRCULATIONAHA.108.827121

53 Nawrot TS, Van Hecke E, Thijs L, et al. Cadmium-related mortality and long-term secular trends in the cadmium body burden of an environmentally exposed population. Environ Health Perspect 2008:116:1620-8, doi:10.1289/ehp 11667

54 Yoshizawa K, Rimm EB, Morris JS, et al. Mercury and the risk of coronary heart disease in men. N Engl J Med 2002;347:1755-60. doi:10.1056/NEJMoa021437

55 Li Q, Nishijo M, Nakagawa H, et al. Relationship between urinary cadmium and mortality in habitants of a cadmium-polluted area: a 22-year follow-up study in Japan. Chin Med J (Engl) 2011:124:3504-9.

56 Barregard L, Sallsten G, Fagerberg B, et al. Blood Cadmium Levels and Incident Cardiovascular Events during Follow-up in a PopulationBased Cohort of Swedish Adults: The Malmö Diet and Cancer Study. Environ Health Perspect 2016;124:594-600

57 Tellez-Plaza M, Navas-Acien A, Menke A, Crainiceanu CM, PastorBarriuso R, Guallar E. Cadmium exposure and all-cause and cardiovascular mortality in the U.S. general population. Environ Health Perspect 2012;120:1017-22. doi:10.1289/ehp.1104352

58 Menke A, Muntner P, Silbergeld EK, Platz EA, Guallar E. Cadmium levels in urine and mortality among U.S. adults. Environ Health Perspect 2009;117:190-6. doi:10.1289/ehp.11236

59 Tellez-Plaza M, Guallar E, Howard BV, et al. Cadmium exposure and incident cardiovascular disease. Epidemiology 2013;24:421-9. doi:10.1097/EDE.0b013e31828b0631

60 Guallar E, Sanz-Gallardo MI, van't Veer P, et al, Heavy Metals and Myocardial Infarction Study Group. Mercury, fish oils, and the risk of myocardial infarction. N Engl / Med 2002;347:1747-54. doi:10.1056/NEJMoa020157
61 Bergdahl IA, Ahlqwist M, Barregard L, et al. Mercury in serum predicts low risk of death and myocardial infarction in Gothenburg women. Int Arch Occup Environ Health 2013;86:71-7. doi:10.1007/s00420012-0746-8

62 Hallgren CG, Hallmans G, Jansson JH, et al. Markers of high fish intake are associated with decreased risk of a first myocardial infarction. $\mathrm{Br}$ Nutr 2001;86:397-404. doi:10.1079/BJN2001415

63 Mozaffarian D, Shi P, Morris JS, et al. Mercury exposure and risk of cardiovascular disease in two U.S. cohorts. N Engl J Med 2011;364:1116-25. doi:10.1056/NEJMoa1006876

64 Virtanen JK, Voutilainen S, Rissanen TH, et al. Mercury, fish oils, and risk of acute coronary events and cardiovascular disease, coronary heart disease, and all-cause mortality in men in eastern Finland. Arterioscler Thromb Vasc Biol 2005;25:228-33.

65 Daneshmand R, Kurl S, Tuomainen TP, Virtanen JK. Associations of serum n-3 and n-6 PUFA and hair mercury with the risk of incident stroke in men: the Kuopio Ischaemic Heart Disease Risk Factor Study (KIHD). Br J Nutr 2016;115:1851-9. doi:10.1017/ S0007114516000982

66 Wennberg M, Bergdahl IA, Hallmans G, et al. Fish consumption and myocardial infarction: a second prospective biomarker study from northern Sweden. Am J Clin Nutr 2011;93:27-36. doi:10.3945/ ajcn.2010.29408

67 Wennberg M, Bergdahl IA, Stegmayr B, et al. Fish intake, mercury, long-chain $\mathrm{n}-3$ polyunsaturated fatty acids and risk of stroke in northern Sweden. Br / Nutr 2007;98:1038-45. doi:10.1017/ S0007114507756519

68 Downer MK, Martínez-González MAG, Gea A, et al, PREDIMED Study Investigators. Mercury exposure and risk of cardiovascular disease: a nested case-control study in the PREDIMED (PREvention with MEDiterranean Diet) study. BMC Cardiovasc Disord 2017;17:9. doi:10.1186/s12872-016-0435-8

69 Kok FJ, Van Duijn CM, Hofman A, et al. Serum copper and zinc and the risk of death from cancer and cardiovascular disease. Am Epidemiol 1988;128:352-9. doi:10.1093/oxfordjournals.aje. a114975

70 Salonen JT, Salonen R, Korpela H, Suntioinen S, Tuomilehto J. Serum copper and the risk of acute myocardial infarction: a prospective population study in men in eastern Finland. Am J Epidemiol 1991;134:268-76. doi:10.1093/oxfordjournals.aje. a116080

71 Marniemi J, Alanen E, Impivaara O, et al. Dietary and serum vitamins and minerals as predictors of myocardial infarction and stroke in elderly subjects. Nutr Metab Cardiovasc Dis 2005;15:188-97. doi:10.1016/j.numecd.2005.01.001

72 Ford ES. Serum copper concentration and coronary heart disease among US adults. Am J Epidemiol 2000;151:1182-8. doi:10.1093/ oxfordjournals.aje.a010168

73 Leone N, Courbon D, Ducimetiere P, Zureik M. Zinc, copper, and magnesium and risks for all-cause, cancer, and cardiovascular mortality. Epidemiology 2006;17:308-14. doi:10.1097/01 ede.0000209454.41466.b7

74 Reunanen A, Knekt P, Marniemi J, Mäki J, Maatela J, Aromaa A. Serum calcium, magnesium, copper and zinc and risk of cardiovascular death. Eur J Clin Nutr 1996;50:431-7.

75 Dubben HH, Beck-Bornholdt HP. Systematic review of publication bias in studies on publication bias. BMJ 2005;331:433-4. doi:10.1136/ bmj.38478.497164.F7

76 Mitchell E, Frisbie S, Sarkar B. Exposure to multiple metals from groundwater-a global crisis: geology, climate change, health effects, testing, and mitigation. Metallomics 2011;3:874-908. doi:10.1039/ c1mt00052g

77 Singh R, Singh S, Parihar P, Singh VP, Prasad SM. Arsenic contamination, consequences and remediation techniques: a review. Ecotoxicol Environ Saf 2015;112:247-70. doi:10.1016/j. ecoenv.2014.10.009

78 Lemaire M, Lemarie CA, Molina MF, et al. Exposure to moderate arsenic concentrations increases atherosclerosis in ApoE-/mouse model. Toxicol Sci . 2011; 122:211-21. doi:10.1093/ toxsci/kfro97

79 Srivastava S, Vladykovskaya EN, Haberzettl P, Sithu SD, D’Souza SE, States JC. Arsenic exacerbates atherosclerotic lesion formation and inflammation in ApoE-/- mice. Toxicol Appl Pharmacol 2009;241:90100. doi:10.1016/j.taap.2009.08.004

80 Ellinsworth DC. Arsenic, reactive oxygen, and endothelial dysfunction. J Pharmacol Exp Ther 2015:353:458-64. doi:10.1124/ jpet.115.223289

81 Druwe IL, Sollome JJ, Sanchez-Soria P, Hardwick RN, Camenisch TD, Vaillancourt RR. Arsenite activates NFKB through induction of C-reactive protein. Toxicol Appl Pharmacol 2012;261:263-70. doi:10.1016/j.taap.2012.04.005

82 Abhyankar LN, Jones MR, Guallar E, Navas-Acien A. Arsenic exposure and hypertension: a systematic review. Environ Health Perspect 2012;120:494-500. doi:10.1289/ehp.1103988 
83 Waghe P, Sarath TS, Gupta P, et al. Arsenic causes aortic dysfunction and systemic hypertension in rats: Augmentation of angiotensin II signaling. Chem Biol Interact 2015;237:104-14. doi:10.1016/j. cbi.2015.06.014

84 Shiue I. Higher urinary heavy metal, arsenic, and phthalate concentrations in people with high blood pressure: US NHANES, 2009-2010. Blood Press 2014;23:363-9. doi:10.3109/08037051. 2014.925228

85 Tseng $\mathrm{CH}$. Cardiovascular disease in arsenic-exposed subjects living in the arseniasis-hyperendemic areas in Taiwan. Atherosclerosis 2008;199:12-8. doi:10.1016/j. atherosclerosis.2008.02.013

86 Tseng $\mathrm{CH}$. Blackfoot disease and arsenic: a never-ending story. J Environ Sci Health C Environ Carcinog Ecotoxicol Rev 2005;23:55-74. doi:10.1081/GNC-200051860

87 Muntner P, Menke A, DeSalvo KB, Rabito FA, Batuman V Continued decline in blood lead levels among adults in the United States: the National Health and Nutrition Examination Surveys. Arch Intern Med 2005:165:2155-61. doi:10.1001/archinte.165.18.215

88 Tong S, von Schirnding YE, Prapamontol T. Environmental lead exposure: a public health problem of global dimensions. Bull World Health Organ 2000;78:1068-77.

89 Fewtrell LKR, Prüss-Üstün A. Lead: assessing the environmental burden of disease at national and local level. World Health Organization, 2003.

90 Ekong EB, Jaar BG, Weaver VM. Lead-related nephrotoxicity: a review of the epidemiologic evidence. Kidney Int 2006;70:2074-84 doi:10.1038/sj.ki.5001809

91 Kinsman GD, Howard AN, Stone DL, Mullins PA. Studies in copper status and atherosclerosis. Biochem Soc Trans 1990;18:1186-8. doi:10.1042/bst0181186

92 Misra R, Bhambal SA, Misra NP, Misra SM. Serum copper, ceruloplasmin \& iron in ischaemic heart disease. Indian Heart J 1978;30:339-44.

93 Kang YJ. Copper and homocysteine in cardiovascular diseases. Pharmacol Ther 2011;129:321-31. doi:10.1016/j. pharmthera.2010.11.004

94 Nakagawa H, Nishijo M, Morikawa Y, et al. Urinary cadmium and mortality among inhabitants of a cadmium-polluted area in Japan. Environ Res 2006;100:323-9. doi:10.1016/j. envres.2005.08.014

95 ATSDR. Toxicological profile for Mercury. Department of Health and Human Services, Public Health Service, 1999.

96 Garland M, Morris JS, Rosner BA, et al. Toenail trace element levels as biomarkers: reproducibility over a 6-year period. Cancer Epidemiol Biomarkers Prev 1993;2:493-7.
97 Clarke R, Shipley M, Lewington S, et al. Underestimation of risk associations due to regression dilution in long-term followup of prospective studies. Am J Epidemiol 1999;150:341-53. doi:10.1093/oxfordjournals.aje.a010013

98 Navas-Acien A, Silbergeld EK, Sharrett R, Calderon-Aranda E, Selvin E, Guallar E. Metals in urine and peripheral arterial disease. Environ Health Perspect 2005;113:164-9. doi:10.1289/ehp.7329

99 Chowdhury R, Alam DS, Fakir II, et al, Cardiology Research Group. The Bangladesh Risk of Acute Vascular Events (BRAVE) Study: objectives and design. Eur J Epidemiol 2015;30:577-87. doi:10.1007/s10654015-0037-2

100 Capable study. Available from: http://www.capable-bangladesh.org/.

101 Lamas GA, Goertz C, Boineau R, et al, TACT Investigators. Effect of disodium EDTA chelation regimen on cardiovascular events in patients with previous myocardial infarction: the TACT randomized trial. JAMA 2013;309:1241-50. doi:10.1001/jama.2013.2107

102 Lei L, Chang X, Rentschler G, et al. A polymorphism in metallothionein $1 \mathrm{~A}$ (MT1A) is associated with cadmium-related excretion of urinary beta 2-microglobulin. Toxicol Appl Pharmacol 2012;265:373-9. doi:10.1016/j.taap.2012.09.006

103 Pierce BL, Kibriya MG, Tong L, et al. Genome-wide association study identifies chromosome 10q24.32 variants associated with arsenic metabolism and toxicity phenotypes in Bangladesh. PLoS Genet 2012;8:e1002522. doi:10.1371/journal.pgen.1002522

104 Zhang H, Ge Y, He P, et al. Interactive Effects of N6AMT1 and As3MT in Arsenic Biomethylation. Toxicol Sci . 2015;146(2):354-62. doi:10.1093/toxsci/kfv101

105 Davey Smith G, Ebrahim S. What can mendelian randomisation tell us about modifiable behavioural and environmental exposures? BMI 2005:330:1076-9. doi:10.1136/bmj.330.7499.1076

106 Sania N, Sauli N, Maithripala S, et al. Time to deliver: report of the WHO Independent High-Level Commission on NCDs. World Health Organisation, 2018.

107 Ghiani A, Fumagalli P, Nguyen Van T, Gentili R, Citterio S. The combined toxic and genotoxic effects of $\mathrm{Cd}$ and $\mathrm{As}$ to plant bioindicator Trifolium repens L. PLoS One 2014;9:e99239. doi:10.1371/journal.pone.0099239

108 Masters SB, Trevor AJ, Katzung BG. Katzung \& Trevor's Pharmacology: Examination \& Board Review (8th ed.). McGraw Hill Medical. 2008.

109 Kosnett MJ. Chelation for heavy metals (arsenic, lead, and mercury): protective or perilous? Clin Pharmacol Ther 2010;88:412-5 doi:10.1038/clpt.2010.132

Supplementary materials: Appendix 1, figures S1S14, and tables S1-S6 